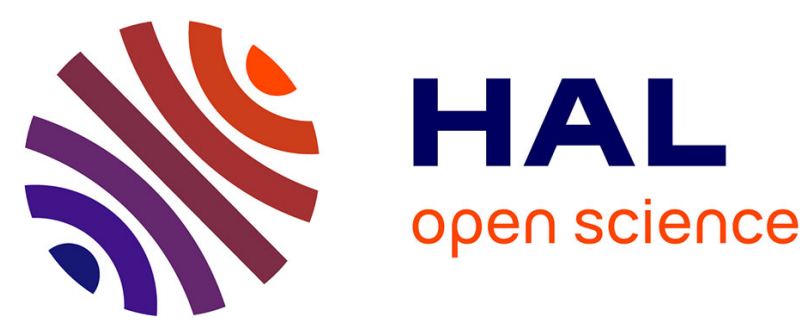

\title{
Distributed Applications and Interoperable Systems
}

Anne Remke, Valerio Schiavoni

\section{To cite this version:}

Anne Remke, Valerio Schiavoni. Distributed Applications and Interoperable Systems: 20th IFIP WG 6.1 International Conference, DAIS 2020, Held as Part of the 15th International Federated Conference on Distributed Computing Techniques, DisCoTec 2020, Valletta, Malta, June 15-19, 2020, Proceedings. Springer International Publishing, LNCS-12135, 2020, Lecture Notes in Computer Science, 978-3-030-50322-2. 10.1007/978-3-030-50323-9 . hal-03223250

\section{HAL Id: hal-03223250 \\ https://hal.inria.fr/hal-03223250}

Submitted on 10 May 2021

HAL is a multi-disciplinary open access archive for the deposit and dissemination of scientific research documents, whether they are published or not. The documents may come from teaching and research institutions in France or abroad, or from public or private research centers.
L'archive ouverte pluridisciplinaire HAL, est destinée au dépôt et à la diffusion de documents scientifiques de niveau recherche, publiés ou non, émanant des établissements d'enseignement et de recherche français ou étrangers, des laboratoires publics ou privés. 


\section{Lecture Notes in Computer Science}

Founding Editors

Gerhard Goos

Karlsruhe Institute of Technology, Karlsruhe, Germany

Juris Hartmanis

Cornell University, Ithaca, NY, USA

Editorial Board Members

Elisa Bertino

Purdue University, West Lafayette, IN, USA

Wen Gao

Peking University, Beijing, China

Bernhard Steffen (1)

TU Dortmund University, Dortmund, Germany

Gerhard Woeginger (1)

RWTH Aachen, Aachen, Germany

Moti Yung

Columbia University, New York, NY, USA 
More information about this series at http://www.springer.com/series/7411 
Anne Remke · Valerio Schiavoni (Eds.)

\section{Distributed Applications and Interoperable Systems}

20th IFIP WG 6.1 International Conference, DAIS 2020

Held as Part of the 15th International Federated Conference on Distributed Computing Techniques, DisCoTec 2020 Valletta, Malta, June 15-19, 2020

Proceedings 


\section{Editors}

Anne Remke

University of Münster

Münster, Germany

\author{
Valerio Schiavoni \\ University of Neuchâtel \\ Neuchâtel, Switzerland
}

ISSN 0302-9743

ISSN 1611-3349 (electronic)

Lecture Notes in Computer Science

ISBN 978-3-030-50322-2

ISBN 978-3-030-50323-9 (eBook)

https://doi.org/10.1007/978-3-030-50323-9

LNCS Sublibrary: SL5 - Computer Communication Networks and Telecommunications

(C) IFIP International Federation for Information Processing 2020

This work is subject to copyright. All rights are reserved by the Publisher, whether the whole or part of the material is concerned, specifically the rights of translation, reprinting, reuse of illustrations, recitation, broadcasting, reproduction on microfilms or in any other physical way, and transmission or information storage and retrieval, electronic adaptation, computer software, or by similar or dissimilar methodology now known or hereafter developed.

The use of general descriptive names, registered names, trademarks, service marks, etc. in this publication does not imply, even in the absence of a specific statement, that such names are exempt from the relevant protective laws and regulations and therefore free for general use.

The publisher, the authors and the editors are safe to assume that the advice and information in this book are believed to be true and accurate at the date of publication. Neither the publisher nor the authors or the editors give a warranty, expressed or implied, with respect to the material contained herein or for any errors or omissions that may have been made. The publisher remains neutral with regard to jurisdictional claims in published maps and institutional affiliations.

This Springer imprint is published by the registered company Springer Nature Switzerland AG The registered company address is: Gewerbestrasse 11, 6330 Cham, Switzerland 


\section{Foreword}

The 15th International Federated Conference on Distributed Computing Techniques (DisCoTec 2020) took place during June 15-19, 2020. It was organized by the Department of Computer Science at the University of Malta, but was held online due to the abnormal circumstances worldwide affecting physical travel.

The DisCoTec series is one of the major events sponsored by the International Federation for Information Processing (IFIP). It comprises three conferences:

- The IFIP WG6.1 22nd International Conference on Coordination Models and Languages (COORDINATION 2020)

- The IFIP WG6.1 19th International Conference on Distributed Applications and Interoperable Systems (DAIS 2020)

- The IFIP WG6.1 40th International Conference on Formal Techniques for Distributed Objects, Components and Systems (FORTE 2020)

Together, these conferences cover a broad spectrum of distributed computing subjects, ranging from theoretical foundations and formal description techniques to systems research issues. As is customary, the event also included several plenary sessions in addition to the individual sessions of each conference, that gathered attendants from the three conferences. These included joint invited speaker sessions and a joint session for the best papers from the respective three conferences.

Associated with the federated event, two satellite events took place:

- The 13th International Workshop on Interaction and Concurrency Experience (ICE 2020)

- The First International Workshop on Foundations of Consensus and Distributed Ledgers (FOCODILE 2020)

I would like to thank the Program Committee chairs of the different events for their help and cooperation during the preparation of the conference, and the Steering Committee and Advisory Boards of DisCoTec and their conferences for their guidance and support. The organization of DisCoTec 2020 was only possible thanks to the dedicated work of the Organizing Committee, including Davide Basile and Francisco "Kiko" Fernández Reyes (publicity chairs), Antonis Achilleos, Duncan Paul Attard, and Ornela Dardha (workshop chairs), Lucienne Bugeja (logistics and finances), as well as all the students and colleagues who volunteered their time to help. Finally, I would like to thank IFIP WG6.1 for sponsoring this event, Springer's Lecture Notes in Computer Science team for their support and sponsorship, EasyChair for providing the reviewing framework, and the University of Malta for providing the support and infrastructure to host the event.

June 2020 


\section{Preface}

This volume contains the papers presented at the 20th IFIP International Conference on Distributed Applications and Interoperable Systems (DAIS 2020), sponsored by the IFIP (International Federation for Information Processing) and organized by the IFIP WG6.1. The DAIS conference series addresses all practical and conceptual aspects of distributed applications, including their design, modeling, implementation, and operation, the supporting middleware, appropriate software engineering methodologies and tools, as well as experimental studies and applications.

DAIS 2020 was meant to be held during June 15-19, 2020, in Valletta, Malta, as part of DisCoTec, the 15th International Federated Conference on Distributed Computing Techniques. However, due to the COVID-19 pandemic, the organizers decided to turn the conference into a virtual event to be held completely online.

There were 30 initial abstract registrations for DAIS, which were then followed by 17 full papers. Each submission was reviewed by up to three Program Committee (PC) members. The review process included an in-depth discussion phase, during which the merits of all papers were discussed by the PC. The committee decided to accept ten full papers, one short paper, and one invited paper.

Accepted papers address challenges in multiple application areas, including system support for machine learning, security and privacy issues, experimental reproducibility and fault-tolerance, as well novel networking approaches for future network generations. Researchers continue the trend of focusing on trusted execution environments, for instance in the case of database systems. Instead, we notice fewer research efforts devoted to blockchain topics.

The virtual conference, especially during these last months full of unpredictable events, was made possible by the work and cooperation of many people working in several committees and organizations, all of which are listed in these proceedings. In particular, we are grateful to the Program Committee members for their commitment and thorough reviews and for their active participation in the discussion phase, and all the external reviewers for their help in evaluating submissions. Finally, we also thankful to the DisCoTec general chair, Adriano Francalanza, and the DAIS Steering Committee chair, Rui Oliveira, for their constant availability, support, and guidance.

June 2020

Anne Remke

Valerio Schiavoni 


\section{Organization}

\section{General Chair}

Adrian Francalanza

University of Malta, Malta

\section{Program Committee Chairs}

Anne Remke

Valerio Schiavoni

\section{Steering Committee}

Rocco De Nicola

Pascal Felber

Kurt Geihs

Alberto Lluch Lafuente

Kostas Magoutis

Elie Najm (Chair)

Manuel Núñez

Rui Oliveira

Jean-Bernard Stefani

Gianluigi Zavattaro

\section{Program Committee}

Pierre-Louis Aublin

Sonia Ben Mokhtar

Sara Bouchenak

Antoine Boutet

Silvia Bonomi

Damiano Di

Francesco Maesa

Davide Frey

Paula Herber

Mark Jelasity

Evangelia Kalyvianaki

Vana Kalogeraki

Rüdiger Kapitza

João Leitão

Daniel Lucani

Miguel Matos

Kostas Magoutis
University of Münster, Germany

University of Neuchâtel, Switzerland
IMT Lucca, Italy

University of Neuchâtel, Switzerland

University of Kasel, Germany

DTU, Denmark

ICS-FORTH, Greece

Télécom ParisTech, France

Universidad Complutense de Madrid, Spain

University of Minho, Portugal

Inria Grenoble, France

University of Bologna, Italy

Keio University, Japan

LIRIS-CNRS, France

INSA, France

INSA, France

Università degli Studi di Roma La Sapienza, Italy

University of Cambridge, UK

Inria, France

University of Münster, Germany

University of Szeged, Hungary

University of Cambridge, UK

Athens University of Economics and Business, Greece

Technical University of Braunschweig, Germany

Universidade Nova de Lisboa, Portugal

Aarhus University, Denmark

INESC-ID, University of Lisboa, Portugal

University of Ioannina, Greece 
Claudio Antares Mezzina

Alberto Montresor

Daniel OKeeffe

Emanuel Onica

Marta Patino

José Orlando Pereira

Hans P. Reiser

Etienne Riviére

Romain Rouvoy

Pierre Sutra

Spyros Voulgaris

\section{Additional Reviewers}

Isabelly Rocha

Philipp Eichhammer

Christian Berger

Vania Marangozova-Martin
University of Urbino, Italy

University of Trento, Italy

Royal Holloway University of London, UK

Alexandru Ioan Cuza University of Iasi, Romania

Universidad Politecnica de Madrid, Spain

Universidade do Minho, INESC-TEC, Portugal

University of Passau, Germany

École Polytechnique de Louvain, Belgium

University of Lille 1, France

Télécom SudParis, France

Athens University of Economics and Business, Greece

\section{DisCoTec Organizing Committee}

Adrian Francalanza

(General Chair)

Davide Basile

(Publicity Chair)

Kiko Fernández-Reyes

(Publicity Chair)

Antonis Achilleos

(Workshops Chair)

Duncan Attard

(Workshops Chair)

Ornela Dardha

(Workshops Chair)
University of Neuchâtel, Switzerland

University of Passau, Germany

University of Passau, Germany

IMAG, France
University of Malta, Malta

ISTI-CNR, Italy

Uppsala University, Sweden

Reykjavik University, Iceland

University of Malta, Malta

University of Glasgow, UK

University of Malta, Malta 


\section{Contents}

\section{Privacy and Security}

On the Trade-Offs of Combining Multiple Secure Processing Primitives

for Data Analytics. . . . . . . . . . . . . . . . . . . . . . .

Hugo Carvalho, Daniel Cruz, Rogério Pontes, João Paulo, and Rui Oliveira

Capturing Privacy-Preserving User Contexts with IndoorHash . . . . . . . . 21 Lakhdar Meftah, Romain Rouvoy, and Isabelle Chrisment

\section{Cloud and Systems}

Towards Hypervisor Support for Enhancing the Performance of Virtual Machine Introspection. . . . . . . . . . . . . . . . . .

Benjamin Taubmann and Hans P. Reiser

Fed-DIC: Diagonally Interleaved Coding in a Federated

Cloud Environment . . . . . . . . . . . . . . . . . . . . . . . . . .

Giannis Tzouros and Vana Kalogeraki

TailX: Scheduling Heterogeneous Multiget Queries to Improve

Tail Latencies in Key-Value Stores . . . . . . . . . . . . . . . . . .

Vikas Jaiman, Sonia Ben Mokhtar, and Etienne Rivière

\section{Fault-Tolerance and Reproducibility}

Building a Polyglot Data Access Layer for a Low-Code Application

Development Platform (Experience Report) . . . . . . . . . . . . . . . . . . .

Ana Nunes Alonso, João Abreu, David Nunes, André Vieira, Luiz Santos, Tércio Soares, and José Pereira

A Comparison of Message Exchange Patterns in BFT Protocols (Experience Report).

Fábio Silva, Ana Alonso, José Pereira, and Rui Oliveira

Kollaps/Thunderstorm: Reproducible Evaluation of Distributed Systems:

Tutorial Paper.

Miguel Matos 


\section{Machine Learning for Systems}

Self-tunable DBMS Replication with Reinforcement Learning . . . . . . . . . .

Luís Ferreira, Fábio Coelho, and José Pereira

DroidAutoML: A Microservice Architecture to Automate the Evaluation

of Android Machine Learning Detection Systems

Yérom-David Bromberg and Louison Gitzinger

\section{Distributed Algorithms}

A Resource Usage Efficient Distributed Allocation Algorithm for 5G

Service Function Chains . . . . . . . . . . . . . . . . . . . .

Guillaume Fraysse, Jonathan Lejeune, Julien Sopena, and Pierre Sens

A Self-stabilizing One-To-Many Node Disjoint Paths Routing Algorithm in Star Networks . . . . . . . . . . . . . . . . . . . . . . . . Rachid Hadid and Vincent Villain 